\title{
Receptor Ativado por Proliferadores de Peroxissoma Gama (PPARy): Estudo Molecular na Homeostase da Glicose, Metabolismo de Lipídeos e Abordagem Terapêutica
}

revisão

\author{
VLADIMIR TAVARES \\ MARIO HIROYUKI HIRATA \\ Rosario D. CREsPo HiRATA
}

Programa de Pós-Graduação em Farmácia - Área de Análises

Clínicas (VT), e Departamento de Análises Clínicas e Toxicológicas (MHH \& RDCH),

Faculdade de Ciências

Farmacêuticas, Universidade de São Paulo, SP

Recebido em 30/08/06

Revisado em 04/12/06 Aceito em 23/02/07

\section{RESUMO}

Os receptores ativados por proliferadores de peroxissoma (PPARs) são fatores de transcrição pertencentes à família de receptores nucleares que regulam a homeostase da glicose, metabolismo de lipídeos e inflamação. Três proteínas, codificadas por genes distintos, têm sido identificadas: PPAR $\alpha$, PPAR $\beta$ e PPAR $\gamma$, que controlam a expressão gênica pela ligação a elementos responsivos específicos (PPREs) localizados na região promotora. Estudos recentes sugerem que a ativação do PPAR pode diminuir a progressão da aterosclerose e aumentar a sensibilidade à insulina, podendo ser um potencial alvo terapêutico para o tratamento de diversas enfermidades, incluindo o diabetes melito do tipo 2 e dislipidemia. Esta revisão destaca os estudos recentes e os avanços das principais funções que esse receptor desempenha no metabolismo, com ênfase nos mecanismos moleculares e eficácia terapêutica. (Arq Bras Endocrinol Metab 2007; 51/4:526-533)

Descritores: Receptor nuclear; Fator de transcrição; Homeostase da glicose; Metabolismo de lipídeos; Inflamação

\section{ABSTRACT}

Peroxisome Proliferator-Activated Receptor Gamma (PPAR $y$ ): Molecular Study In Glucose Homeostasis, Lipid Metabolism and Therapeutic Approach.

The peroxisome proliferators-activated receptors (PPARs) are transcription factors belonging to the family of nuclear receptors that regulate glucose homeostasis, lipid metabolism and inflammation. Three proteins, encoded by distinct genes, have been identified: PPAR $\alpha$, PPAR $\beta$ and PPAR $\gamma$, which control gene expression by binding to specific response elements (PPREs) in the promoters. Recent studies suggest that activation of PPAR $\gamma$ might decrease atherosclerosis progression and increase the insulin sensitivity, might be a potential therapeutic target for the treatment of a diverse array of disorders, including type 2 diabetes and dyslipidaemia. This review highlights recent studies, which have advanced our understanding of the pivotal role that this receptor plays in metabolism, with particular reference to the molecular mechanisms and therapeutic efficacy. (Arq Bras Endocrinol Metab 2007;51/4:526-533)

Keywords: Nuclear receptor; Transcription factor; Glucose homeostasis; Lipid metabolism; Inflammation 
$\mathrm{P}$ PARs (RECEPTORES ATIVADOS por proliferadores de peroxissoma) são fatores de transcrição da família de receptores nucleares, caracterizados por seu padrão de distribuição nos tecidos e por sua função metabólica. Estruturalmente podem ser incluídos como membros da subfamília de receptores que incluem o receptor do hormônio da tireóide (TR), receptor do ácido retinóico (RAR) e o receptor da vitamina D3 (VDR).

Três proteínas, codificadas por genes distintos, têm sido identificadas: PPAR $\alpha$, PPAR $\beta$ e PPAR $\gamma$. Os PPARs são fatores de transcrição ligantes dependentes que regulam a expressão do gene-alvo pela ligação a específicos PPREs (elementos responsivos aos proliferadores de peroxissoma) situados em sítios regulatórios de cada gene. O receptor liga-se ao PPRE como um heterodímero, juntamente com um fator protéico adicional, o receptor do ácido 9-cis retinóico (RXR). Sob atuação de agonistas, a conformação do PPAR é alterada e estabilizada, criando um sítio de ligação, com posterior recrutamento de coativadores transcricionais, resultando em aumento na transcrição gênica (figura 1 ).

O PPAR foi originalmente identificado em 1990 (1) com a primeira clonagem (PPAR $\alpha$ ) ocorrendo durante a pesquisa do alvo molecular para agentes proliferadores de peroxissoma em roedores. Desde então, numerosos ácidos graxos e derivados, incluindo uma variedade de eicosanóides e prostaglandinas, têm sido identificados como ligantes para os PPARs, tendo também sido demonstrado serem alvos para numerosas classes de compostos sintéticos, utilizados no tratamento do diabetes e dislipidemias. Portanto, o conhecimento dos mecanismos moleculares e fisiológicos destes receptores torna-se extremamente importante, quer no desenvolvimento como na utilização de drogas para o tratamento de doenças metabólicas.

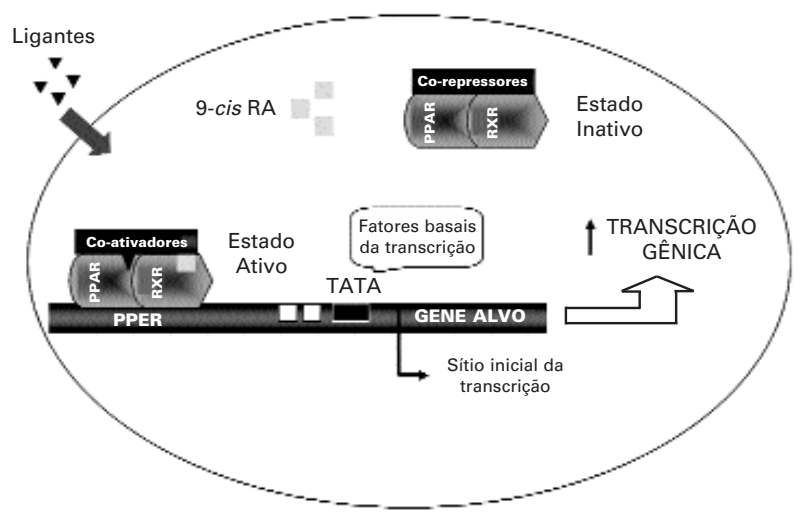

Figura 1. Mecanismo de ativação transcricional pelo PPAR: Requer a liberação do complexo co-repressor (atividade deacetilase da histona), feito por um ligante, e o recrutamento de complexo co-ativador (atividade acetiltransferase). O complexo PPAR:RXR ativado liga-se ao PPRE, produzindo alteração na estrutura da cromatina, originando uma estrutura transcricionalmente competente.

\section{ESTRUTURA DO RECEPTOR}

Os PPARs, como outros receptores nucleares, possuem estrutura modular formada por domínios funcionais (2): domínio A/B (NH2-terminal), pouco conservado entre as três isoformas de PPARs, cujo estado de fosforilação contribui para a modulação da atividade do PPAR $\alpha$ e $\gamma$. Está localizado próximo ao sítio de ativação transcricional independente de ligante (AF-1); domínio C (ou DBD - DNA binding domain), contém os dedos de zinco, que são dois arranjos protéicos constituídos de uma $\alpha$-hélice e uma folha $\beta$-pregueada, mantidas unidas por um íon de zinco na região central, que confere maior estabilidade de dobramento, permitindo associações firmes quando da ligação aos PPREs na região regulatória de genes responsivos ao PPAR; região $\mathrm{D}$, importante como cofator e a região $\mathrm{EF}$ (COOH-terminal), a qual possui o domínio LBD (ligand binding domain) e o sítio de ativação transcricional dependente de ligante (AF-2) (3). Os domínios DBD e LBD são as regiões mais conservadas em todos os PPARs.

\section{RXR E HETERODIMERIZAÇÃO}

Os PPARs formam heterodímeros com o receptor do ácido 9-cis retinóico (RXR) (4). Assim como os PPARs, existem três formas distintas de RXR: RXR $\alpha$, $\beta$ e $\gamma(5)$, apresentando distribuição distinta nos tecidos (6). Quanto aos ligantes, são ativados pelo ácido 9 -cis retinóico (7) e por ligantes sintéticos que são mais potentes e específicos (8).

Além disso, agonistas sintéticos de RXR podem ativar o complexo e exercer atividade antidiabética similar às observadas com PPARs em modelos de camundongos no diabetes do tipo 2 (9). É importante também destacar que os PPARs são incapazes de se ligarem ao DNA como monômeros, cuja propriedade tem sido atribuída à região N-terminal.

\section{CO-FATORES}

Vários co-fatores, tanto ativadores como repressores, que capacitam os receptores nucleares a iniciar ou suprimir o processo de transcrição, foram identificados (10). Vários co-ativadores, por exemplo, SRC-1 (coativador 1 do receptor de esteróides), possuem atividade histona acetilase que pode remodelar a estrutura da cromatina, deixando-a mais frouxa e facilitando a atividade transcricional. $\mathrm{O}$ co-repressor $\mathrm{N}-\mathrm{CoR}$ (co- 
repressor núcleo receptor) é uma proteína que interage com o receptor nuclear livre, mediando um sinal repressivo para o promotor no qual o complexo está ligado (11).

\section{PPRES (PEROXISOME PROLIFERATOR RESPOND ELEMENT)}

Os PPREs são formados por dois hexanucleotídeos com uma seqüência de consenso AGGTCA A AGGTCA, separada por um único nucleotídeo, também chamado de DR-1 e localizado na região promotora dos genes que estão sob seu controle transcricional (12). Seqüências com essas características têm sido encontradas em numerosos genes relacionados ao PPAR, tais como a acil-CoA oxidase e a proteína de ligação aos ácidos graxos nos adipócitos (aP2) (13).

\section{PPAR $\gamma$}

O gene do PPAR $\gamma$ foi mapeado no cromossomo 3 (14), região $3 \mathrm{p} 25$, dando origem a três RNA mensageiros: PPAR $\gamma 1, \operatorname{PPAR} \gamma 2$ e PPAR $\gamma 3$, que diferem em sua extremidade 5', como conseqüência de diferentes promotores e ao splicing alternativo. O PPAR $\gamma \mathrm{I}$ é codificado por oito exons, compreendendo dois exons $\gamma 1$ específicos na região 5' não traduzida, Al e A2, e seis exons comuns aos três RNA mensageiros. PPAR 2 , codificado por sete exons, sendo o exon B específico para este receptor, codificando 28 aminoácidos na região $\mathrm{N}$-terminal, e PPAR $\gamma 3$, que codifica a mesma proteína que PPAR $\gamma 1$, sendo controlado por um promotor distinto, localizado na região 5', próxima a A2 (15).

PPAR $\gamma 1$ é expresso em uma ampla variedade de tecidos, incluindo coração, cólon, intestino delgado e grosso, rins, pâncreas e baço. PPAR $\gamma 2$ é expresso no tecido adiposo (16) e PPAR 33 tem expressão restrita a macrófagos e intestino grosso (15).

\footnotetext{
PPARy no mecanismo de sensibilização à insulina - aspectos moleculares

PPAR y é necessário e suficiente para diferenciar adipócitos. A introdução de PPAR $\gamma$ em fibroblastos, na presença de ligantes fracos para o PPAR, induziu diferenciação destas células em adipócitos (17). Outros pesquisadores, trabalhando com camundongos destituídos de PPAR $\gamma$, observaram que estes apresentavam reduzida quantidade de tecido adiposo (18) ou exibiam extrema lipodistrofia.
}

Nos adipócitos, o PPAR $y$ regula a expressão de numerosos genes envolvidos no metabolismo de lipídeos, incluindo aP2 (17), acil-CoA sintetase (19) e lipase lipoprotéica (LPL) (3). Também controla a expressão da proteína transportadora de ácidos graxos 1 (FATP-1) e CD36 (20), ambos envolvidos na captação de lipídeos pelos adipócitos. Esses genes também apresentam elementos responsivos (PPREs) em sua região regulatória.

Dado que PPAR $\gamma$ é predominantemente expresso no tecido adiposo, a hipótese prevalente a respeito dos agonistas envolvidos na ação direta em adipócitos é que possuam, também, efeitos secundários em tecidos insulino-responsivos, tais como muscular esquelético e fígado. A perda da eficiência em reduzir os valores de glicose, pela rosiglitazone, em camundongos com severa resistência à insulina, onde o tecido adiposo está praticamente ausente, está de acordo com esta afirmação (21).

Análises da expressão de RNA mensageiro em tecidos revelaram que genes contendo PPREs, induzidos no tecido adiposo, eram suprimidos no tecido esquelético. Entretanto, agonistas do PPAR $\gamma$, com ação metabólica benéfica em tecidos distantes (músculo e fígado), provavelmente estão envolvidos com efeitos combinados, pois acentuam a captação, mediada pela insulina, no tecido adiposo, estoque e catabolismo de ácidos graxos livres, induz a produção de fatores derivados dos adipócitos com potencial ação sensibilizadora para a insulina e suprimem os níveis circulantes e/ou ações de fatores derivados do tecido adiposo que causam insulino-resistência, como o fator de necrose tumoral alfa (TNF $\alpha$ ) ou resistina (22). Portanto, a ativação do PPARy poderia induzir um aumento do clearance de ácidos graxos pelo tecido adiposo, com conseqüente diminuição na concentração plasmática e transporte para o músculo. Essa diminuição de ácidos graxos no músculo aumenta a sensibilidade à insulina (23); a atividade adipogênica do PPAR $\gamma$ contribui de forma importante neste efeito.

Embora a função do PPAR $\gamma$ no desenvolvimento do tecido adiposo esteja bem estabelecida, seu nível reduzido nos tecidos metabolicamente importantes na homeostase da glicose, por exemplo, músculo esquelético, fígado e células $\beta$ pancreáticas, aumenta a questão de sua possível importância fisiológica e farmacológica nesses sítios (24). Além disso, sua alta expressão em macrófagos é bem estabelecida em indivíduos obesos, cuja infiltração nos tecidos adiposos com função comprometida pode ser patologicamente importante (25). De qualquer forma, a importância da fisiopatologia do PPAR $\gamma$ nos tecidos e células não adiposas ainda não está clara (26). 


\section{Alterações moleculares no PPARy e doença metabólica}

Evidências da ligação do PPAR $\gamma$ com a ação da insulina, em humanos, também tem sido observada pelo estudo de alterações genéticas, de ocorrência natural, no receptor PPAR $\gamma$. Foram identificadas, até o momento, sete mutações pontuais, com fenótipo associado à obesidade $(27,28)$, insulino-resistência, diabetes e hipertensão (29), lipodistrofia parcial e doença arterial coronariana (30-32) e aumento dos níveis de leptina no plasma em associação com obesidade (33) (tabela 1).

Um polimorfismo relativamente comum, localizado na porção amino-terminal da isoforma PPAR $\gamma 2$, substituindo a prolina por alanina no códon 12 (Prol2Ala), tem sugerido apresentar efeito protetor contra o risco de desenvolver diabetes melito do tipo 2 . Este alelo, cuja freqüência varia de 2 a $23 \%$ em diferentes grupos étnicos (34), foi originalmente associado com baixo índice de massa corpórea (IMC) (35) e melhor sensibilidade à insulina (36), porém alguns questionamentos têm sido propostos em relação a esses estudos $(37,38)$. Após demonstrarem que portadores do alelo Ala1 2 possuíam o receptor PPAR $\gamma$ com capacidade deficiente em ligar e transativar genes-alvo, Deeb e cols. (35) concluíram que um mecanismo molecular estaria envolvido para explicar as diferenças entre os genótipos, sugerindo que a diminuição da massa de tecido adiposo, como evidenciado pelo IMC, poderia melhorar a sensibilidade à insulina. Esta hipótese é consistente com a observação de que PPAR $\gamma 2$ tem papel regulatório único na adipogênese (39). No mesmo estudo, uma significante razão de chances $(\mathrm{RC}=4,35 ; P=0,028)$ para a associação do alelo Prol 2 com diabetes melito do tipo 2 foi observada entre grupos de segunda geração de japoneses americanos.

Sabe-se, também, que o gene PPAR $\gamma 2$ é expresso nas células $\beta$ pancreáticas (40), portanto os portadores do alelo Alal2 podem ter a função dessas células comprometidas pela reduzida capacidade em ativar a transcrição, com provável diminuição na secreção de insulina (41).

Tabela 1. Relação das mutações do PPAR $\gamma$ descritas até o momento.

\begin{tabular}{lcccc}
\hline Codon & Nucleotídeo & Resíduos & Acesso & Refs. \\
\hline 12 & cCCA-GCA & Pro-Ala & CM 981614 & 27 \\
113 & CCA-CAA & Pro-GIn & CM 981615 & 28 \\
318 & cGTG-ATG & Val-Met & CM 993365 & 29 \\
388 & TTTg-TTA & Phe-Leu & CM 023124 & 31 \\
425 & cCGC-TGC & Arg-Cys & CM 020182 & 32 \\
477 & CACg-CAT & His-His & CM 994587 & 33 \\
495 & CCG-CTG & Pro-Leu & CM 993366 & 29 \\
\hline
\end{tabular}

Fonte: Human Gene Mutation Database, Cardiff (HGMD)
Um grande estímulo inicial em relação ao polimorfismo Prol2Ala, como um locus susceptível ao diabetes, foi evidenciado quando estudos sugeriram associação estatisticamente significante com o risco da doença $(42,43)$. Enquanto o estudo da alteração molecular Prol2Ala sugeriu forte ligação genética com o diabetes melito do tipo 2, provavelmente a maior evidência da ligação direta entre sensibilidade à insulina e a ação do PPAR $\gamma$, em humanos, foi o estudo de indivíduos heterozigotos para uma mutação no domínio de ligação LBD, resultando em significante disfunção do receptor $(29,31,32)$. No trabalho de Barroso e cols. (29), três indivíduos heterozigotos para uma das duas mutações encontradas (Val290Met e Pro467Leu) no PPAR $\gamma$ apresentavam acentuada resistência à insulina e início de diabetes melito do tipo 2, o que evidenciava a ligação entre a ação do PPAR $\gamma$ e a regulação da homeostase da glicose em mamíferos. Os indivíduos afetados apresentavam numerosas características de síndrome metabólica, incluindo: dislipidemia, hipertensão e hiperuricemia. Quando se verificaram as características moleculares desses receptores, obteve-se como resultado que os receptores mutantes demonstravam regulação transcricional prejudicada.

Deve-se, também, salientar que discrepâncias em estudos epidemiológicos podem surgir como conseqüência da ligação de seqüências variantes, com significância funcional, presentes no gene do PPAR $\gamma$, que podem ter efeito oposto ao polimorfismo Prol2Ala (44). Entretanto, somente um número limitado de estudos tem examinado a associação de haplotipos com parâmetros metabólicos (45). É importante observar que determinados fatores ambientais (dieta e exercício físico) podem estar influenciando os efeitos das variações genéticas no gene do PPAR $\gamma$ (26).

Um segundo polimorfismo, descrito por Meirhaeghe e cols. (33), resultando de uma substituição silenciosa de "C" para "T" (Cl61T) no exon 6 do gene PPAR $\gamma$, demonstrou que caucasianos obesos franceses, portadores do alelo 161T, apresentavam maior concentração plasmática de leptina em comparação com os portadores do alelo 161C. Em oposição a este achado, Arashiro e cols. (46) não encontraram essa associação quando estudaram crianças obesas no Japão. Outro estudo sugere que este polimorfismo não está associado com variáveis relacionadas ao diabetes melito do tipo 2 ou resistência à insulina, porém uma reduzida concentração de triglicérides foi observada em mulheres portadoras do alelo $161 \mathrm{~T}$ (47). 


\section{PPARy e aterosclerose}

Aterosclerose é uma doença complexa em que muitos fatores podem estar envolvidos. É caracterizada pelo acúmulo gradual de lipídeos na parede arterial (placa aterosclerótica), freqüentemente levando a obstrução repentina do fluxo sanguíneo após ruptura desta placa. A disfunção do endotélio resulta da inflamação crônica da parede vascular, proliferação de células muscular lisa e formação das foam cells. PPAR $\gamma$ pode afetar na formação destas foam cells, modulando a resposta inflamatória e influenciando a estabilidade da placa $(48,49)$.

Além disso, vários outros estudos reportam que ligantes do PPAR $\gamma$ podem reduzir a liberação de citoquinas inflamatórias (TNF- $\alpha$ e Interleucina-6) dos macrófagos, resultando num efeito anti-aterogênico (50). Ocorre, também, que PPAR $\gamma$ pode reduzir a expressão das metaloproteinases (MMP-9), as quais estão implicadas na desestabilização das placas (51). É importante ressaltar que PPAR $\gamma$ também pode promover aterosclerose, na medida em que estimula a captação de LDL oxidada, um evento crítico na formação das foam cells, cujo mecanismo foi proposto por Tontonoz e cols. (52). Estes resultados conflitantes podem ser confrontados por estudos mais recentes que examinam, pormenorizadamente, a via de sinalização relacionada ao tráfego de lipídeos nos macrófagos, com identificação de alvos adicionais regulados pelo PPARy (54), sugerindo, desta forma, que um ou mais mecanismos possam estar envolvidos.

Evidências da ação do PPAR $\gamma$ no metabolismo do tecido adiposo foram descritas por Ristow e cols. (28), que identificaram uma mutação no codon 115 (Prol15Gln) no gene do PPAR $\gamma 2$, em indivíduos da Alemanha, sendo associada com severa obesidade. Ocorre que, em estudos anteriores, a fosforilação da porção adjacente serina (Ser 114) reduzia a capacidade do receptor em mediar a diferenciação de adipócitos e acúmulo de lipídeos (53), especulando-se, por este motivo, que essa alteração molecular possa prejudicar tal fosforilação, com aumento de sua atividade transcricional, ação na adipogênese e obesidade.

\section{Potencial terapêutico para os ligantes do PPARy}

A importância do PPAR $\gamma$ no metabolismo humano começou em 1995, quando foi identificado um receptor para a classe de um grupo de drogas, caracterizadas por aumentar a sensibilidade a insulina, denominadas tiazolidinedionas (TZD) (55). As três drogas pertencentes a este grupo (pioglitazona, rosiglitazona e troglitazona), potentes e altamente seletivas para o PPAR $\gamma$, têm sido utilizadas em larga escala na prática clínica, embora o emprego da troglitazona tenha sido descontinuado, haja vista o aparecimento de casos de hepatotoxicidade. Resultados de grandes estudos clínicos têm consistentemente evidenciado que as TZDs produzem melhora significativa no controle glicêmico, destacando-se, neste contexto, o estudo DREAM (Diabetes Reduction Assessment with ramipril and rosiglitazone Medication) em que os autores sugerem que a terapia com rosiglitazona $(8 \mathrm{mg} / \mathrm{dia}$, durante 3 anos) e melhora no estilo de vida reduzem substancialmente o risco do desenvolvimento de diabetes em aproximadamente dois terços, oferecendo, desta forma, nova abordagem preventiva que pode ser tão ou mais efetiva do que somente recomendações sobre estilo de vida (56).

Ressalta-se, também, que estudos com o clamp hiperinsulinêmico confirmam a melhora da sensibilidade a insulina no organismo, para as três drogas $(57,58)$, com disponibilidade aumentada para a glicose, embora com menor índice de supressão da produção de glicose hepática (59). Deve-se, também, levar em consideração que a utilização clínica das TZDs é significantemente limitada pela ocorrência de retenção de líquidos, hemodiluição e falência cardíaca em mais de $15 \%$ dos pacientes (60).

\section{Ação das TZDs no tecido adiposo}

Tendo em vista a função bem estabelecida das TZDs e PPAR $\gamma$ na adipogênese, a sensibilização a insulina pode ser interpretada como resultado direto da capacidade do PPAR $\gamma$ em expandir o tecido adiposo, embora as TZDs sejam utilizadas para acentuar a sensibilidade a insulina em pacientes com diabetes melito do tipo 2, o qual é freqüentemente acompanhado pelo desenvolvimento de excesso desse tecido (26). Este paradoxo pode ser parcialmente explicado pela resposta seletiva do tecido adiposo para a ativação do PPAR $\gamma$. Em seres humanos, o tratamento com as TZDs é acompanhado de acúmulo seletivo de tecido adiposo subcutâneo (61) e concomitante perda de mudança ou redução no tecido adiposo visceral. Além disso, alguns estudos ex vivo relacionados a diferenciação de préadipócitos têm mostrado que essas células no tecido subcutâneo abdominal diferenciam em resposta as TZDs mais prontamente do que as células dos depósitos viscerais do mesmo indivíduo (62). No entanto, ainda não é conhecido se o tratamento com as TZDs aumenta igualmente a massa subcutânea em todas as regiões do corpo, questão esta extremamente relevante, haja vista a importância das diferenças metabólicas e funcionais dos diferentes tecidos (abdominal e subcutâneo) (63). 
Um mecanismo pelo qual a ação das TZDs, no tecido adiposo, possa influenciar a sensibilidade a insulina em órgãos insulino-sensíveis mais distantes é a modificação do perfil dos hormônios secretados por esse tecido, que é capaz de produzir uma variedade de pequenas moléculas com atividade autócrina, parácrina ou endócrina, denominadas de adipocitoquinas. A molécula que melhor caracterização apresenta, dentro destes compostos, denomina-se adiponectina, que se apresenta como candidata a mediar os efeitos de sensibilização a insulina pelas TZDs. Essa molécula está presente em grande quantidade no plasma (64), correlacionando-se diretamente com sensibilidade a insulina $(65,66)$ e inversamente com a massa do tecido adiposo (67). Além disso, as TZDs aumentam a expressão do gene da adiponectina e níveis de proteínas plasmáticas (68).

\section{Ação das TZDs no tecido muscular}

Embora a concentração da proteína PPAR $\gamma$ seja relativamente baixa no músculo esquelético (69), a massa muscular total e sua função como sítio de $70 \%$ de disponibilidade de glicose mediada pela insulina em seres humanos sugere que fisiologicamente o PPAR $\gamma$ tenha importantes funções. As TZDs, in vitro, têm sido relacionadas ao aumento da captação de glicose estimulada pela insulina, quando em meio de cultura com células de músculo esquelético, que é mediada pelo aumento da atividade, estimulada pela insulina, do PI3K (fosfatidil-inositol 3 quinase) e translocação do GLUT4 (70), porém a importância fisiológica do PPARy no músculo esquelético permanece incerta.

\section{CONSIDERAÇÕES FINAIS}

Desde a descoberta dos PPARs na década de noventa, está clara a sua participação na regulação genética de vias complexas do metabolismo em mamíferos, porém mais pesquisas serão necessárias para compreender a complexa relação dos mecanismos moleculares entre polimorfismos ou mutações e a função do PPAR $\gamma$ como um importante regulador no metabolismo de carboidratos, lipídeos e sensibilidade a insulina. Devese, também, salientar que há muito o que aprender sobre sua utilidade como alvo terapêutico.

\section{REFERÊNCIAS}

1. Isseman I, Green S. Activation of a member of the steroid hormone receptor superfamily by peroxisome proliferators. Nature 1990;347:645-9.
2. Laudet V, Hanni C, Coll J. Evolution of the nuclear receptor gene superfamily. EMBO 1992;11:1003-13.

3. Schoonjans K, Staels B, Auwerx J. Role of the peroxisome proliferators activated receptor (PPAR) in mediating effects of fibrates and fatty acids on gene expression. J Lipid Res 1996;37:907-25.

4. Werman A, Hollenbert A, Solanes G. Ligand-independent activation domain in the $\mathrm{N}$ terminus of peroxisome proliferators-activated receptor gamma. Differential activity of PPAR 1 and 2 isoforms and influence of insulin. J Biol Chem 1997;272:20230-5.

5. Chambon P. A decade of molecular biology of retinoic acid receptors. FASEB J 1996;10:940-54.

6. Mangelsdorf DJ, Evans RM. The RXR heterodimers and orphan receptors. Cell 1995;83:841-50.

7. Mangelsdorf DJ, Borgmeyer U, Heyman RA. Characterization of three RXR genes that mediate the action of 9 -cis retinoic acid. Genes Dev 1992;6:329-44.

8. Boehm M, Zhang L, Zhi L, McClurg M, Berger E, Wagoner M, et al. Design and synthesis of potent retinoid $X$ receptor selective ligands that induce apoptosis in leukemia cells. $J$ Med Chem 1995;38:3146-55.

9. Mukherjee R, Davies PJA, Crombie DL. Sensitization of diabetic and obese mice to insulin by retinoid $X$ receptor agonists. Nature 1997;386:407-10.

10. Xu L, Glass CK, Rosenfeld, MG. Coactivator and corepressor complexes in nuclear receptor function. Curr Opin Genet Dev 1999;9:140-7.

11. Direnzo J, Soderstrom M, Kurokawa R, Ogliastro MH, Ricote $\mathrm{M}$, Ingrey $\mathrm{S}$, et al. Peroxisome proliferators-activated receptors and retinoic acid receptors differentially control the interactions of retinoid $x$ receptor heterodimers with ligands, coactivators, and corepressors. Mol Cell Biol 1997;17:2166-76.

12. Gearing KL, Göttlicher M, Teboul M, Widmark E, Gustafsson JA. Interaction of the peroxisome proliferators-activated receptor and retinoid $X$ receptor. Proc Natl Acad Sci 1993:90:1440-4.

13. Wahli W, Braissant O, Desvergne B. Peroxisome proliferator activated receptors: transcriptional regulators of adipogenesis, lipid metabolism and more. Chem Biol 1995;2:261-6.

14. Greene MF, Blumberg B, McBride OW, Yi AF, Kronquist K, Kwan $\mathrm{K}$, et al. Isolation of the human peroxisome proliferators activated receptor gamma cDNA: expression in hematopoietic cell, and chromosomal mapping. Gene Expr 1995;4:281-99.

15. Fajas L, Fruchart JC, Auwerx J. PPAR $\gamma 3$ mRNA: a distinct PPAR $\gamma$ mRNA subtype transcribed from an independent promoter. Febs Letts 1998;438:55-60.

16. Fajas L, Auboeuf D, Raspe E. The organization, promoter analysis, and expression of the human PPAR $\gamma$ gene. J Biol Chem 1997;272:18779-89.

17. Tontonoz $\mathrm{P}, \mathrm{Hu}$ E, Spiegelman BM. Stimulation of adipogenesis in fibroblasts by PPAR $\gamma 2$, a lipid activated transcription factor. Cell 1994;79:1147-56.

18. Barak Y, Nelson MC, Ong ES. PPAR is required for placental, cardiac, and adipose tissue development. Mol Cell 1999;4:585-95.

19. Schoonjans K, Watanabe M, Suzuki H. Induction of the acylcoenzyme A synthetase gene by fibrates and fatty acids is mediated by a peroxisome proliferators response element in the C promoter. J Biol Chem 1995;270:19269-76.

20. Sfeir Z, Ibrahimi A, Amri E. Regulation of FAT/CD36 gene expression: further evidence in support of a role of the protein in fatty acid binding/transport. Prostaglandins Leukot Essent Fatty Acids 1997;57:17-21.

21. Chao L, Marcus SB, Mason MM. Adipose tissue is required for the antidiabetic, but not the hypolipidemic, effect of thiazolidinediones. J Clin Invest 2000;106:1221-8.

22. Stefan N, Fritsche A, Haring H, Stumboll M. Effect of experimental elevation of free fatty acids on insulin secretion and insulin sensitivity in healthy carriers of the Pro12Ala polymorphism of the peroxisome proliferators-activated receptor- $\gamma 2$ gene. Diabetes 2001;50:1143-8. 
23. Randle PJ, Garland PB, Hales CN, Newsholme EA. The glucose-fatty acid cycle: its role in insulin sensitivity and metabolic disturbances of diabetes mellitus. Lancet 1991;1:7859.

24. Loviscah M. Distribution of PPARs in human skeletal muscle and adipose tissue: relation to insulin action. Diabetologia 2000;43:304-11.

25. Weisberg SP. Obesity is associated with macrophage accumulation in adipose tissue. J Clin Invest 2003;112:1796808.

26. Semple RK, Chatterjee VKV, O'Rahilly S. PPAR $\gamma$ and human metabolic disease. J Clin Invest 2006;116:581-9.

27. Beamer BA, Yen CJ, Andersen RE, Muller D, Elahi D, Cheskin LJ, et al. Association of the Pro12Ala variant in the Peroxisome Proliferator-Activated Receptor- $\gamma 2$ gene with obesity in two Caucasian populations. Diabetes 1998;47:1806-8.

28. Ristow M, Muller DW, Pfeiffer A, Krone W, Kahn CR. Obesity associated with a mutation in a genetic regulator of adipocyte differentiation. N Engl J Med 1998;339:953-9.

29. Barroso I, Gurnell M, Crowley VEF, Agostini M, Schwabel JW, Soos, MA, et al. Dominant negative mutations in human PPAR $\gamma$ associated with severe insulin resistance, diabetes mellitus and hypertension. Nature 1999;402:880-3.

30. Wang XL, Oosterhof J, Duarte N. Peroxisome proliferatorsactivated receptor $\gamma \mathrm{C} 161-\mathrm{T}$ polymorphism and coronary artery disease. Cardiovasc Res 1999;44:588-94.

31. Hegele RA, Henian C, Frankowski C, Mathews ST, Leff T. PPAR $\gamma$ F388L, a transactivation-deficient mutant, in familial partial lipodystrophy. Diabetes 2002;51:3586-90.

32. Agarwal AK, Garg A. A novel heterozygous mutation in peroxisome proliferators-activated receptor- $\gamma$ gene in a patient with familial partial lipodystrophy. J Clin Endocrinol Metab 2002:87:408-11.

33. Meirhaeghe A, Fajas L, Helbecque N, Cottel D, Lebel P, Dallongeville J, et al. A genetic polymorphism of the peroxisome proliferators-activated receptor $\gamma$ gene influences plasma leptin levels in obese humans. Hum Mol Genet 1998;7:435-40.

34. Stumvoll $M$, Haring $H$. The peroxisome proliferators-activated receptor- $\gamma 2$ Pro12Ala polymorphism. Diabetes 2002:51:2341-7.

35. Deeb SS, Fajas L, Nemoto M, Pihlajamaki J, Mykkanen L, Kuusisto J, et al. A Pro12Ala substitution in PPAR2 associated with decreased receptor activity, lower body mass index and improved insulin sensitivity. Nat Genet 1998;20:287-7.

36. Tavares V, Hirata RDC, Rodrigues AC, Monte O, Salles JEN, Scallissi N, et al. Association between Pro12Ala polymorphism of the PPAR $\gamma 2$ gene and insulin sensitivity in Brazilian patients with type 2 diabetes mellitus. Diabetes Obes Metab 2005;7:605-11.

37. Ek J, Andersen G, Urhammer SA, Hanse L, Carstensen B, Borch JK. Studies of the Pro12Ala polymorphism of the peroxisome proliferators-activated receptor $\gamma 2$ gene in relation to insulin sensitivity among glucose tolerant Caucasians. Diabetologia 2001;44:1170-6.

38. Sanchez JLG, Rios MS, Pérez CF, Laakso M, Larrad MTM. Effect of the Pro12Ala polymorphism of the peroxisome proliferator-activated receptor $\gamma 2$ gene on adiposity, insulin sensitivity and lipid profile in the Spanish population. Eur J Endocrinol 2002;147:495-501.

39. Ren D, Collingwood TN, Rebar EJ, Wolfe AP, Camp HS. PPAR $\gamma$ knockdown by engineered transcription factors: exogenous PPAR $\gamma 2$ but not PPAR $\gamma 1$ reactivates adipogenesis. Gene Dev 2002;16:27-32.

40. Dubois M, Pattou F, Kerr-Conte H. Control of the peroxisomal $\beta$-oxidation pathway by a novel family of nuclear hormone receptors. Cell 2000;43:1165-9.

41. Mori H, Ikegami H, Kawaguchi Y. The Pro12Ala substitution in PPAR $\gamma$ is associated with resistance to development of diabetes in the general population. Diabetes 2001:50:891-4

42. Hara K, Okada T, Tobe K, Yasuda K, Mori Y, Kadowaki H, et al. The Pro12Ala polymorphism in PPAR2 may confer resistance to type 2 diabetes. Biochem Biophys Res Commun 2000;271:212-6.
43. Meirhaeghe A, Fajas L, Helbecque N, Cottel D, Auwerx J, Deeb SS, et al. Impact of the peroxisome proliferator activated receptor- $\gamma 2$ Pro12Ala polymorphism on adiposity, lipids and non-insulin-dependent diabetes mellitus. Int $J$ Obes Relat Metab Disord 2000;24:195-9.

44. Meirhaeghe A, Cottel D, Amouyel P, Dallongeville J. Association between peroxisome proliferators-activated receptor $\gamma$ haplotypes and the metabolic syndrome in French men and women. Diabetes 2005;54:3043-8.

45. Meirhaeghe A. Study of a new PPAR $\gamma 2$ promoter polymorphism and haplotype analysis in a French population. Mol Genet Metab 2005;85:140-8.

46. Arashiro R, Katsuren K, Fukuyama S, Ohta T. Effect of Trp64Arg mutation of the $\beta 3$-adrenergic receptor gene and C161T substitution of the peroxisome proliferators activated receptor $\gamma$ gene on obesity in Japanese children. Pediatr Int 2003:45:135-41.

47. Tavares V, Hirata RDC, Rodrigues AC, Monte O, Salles JEN, Scallissi $\mathrm{N}$ et al. Effect of the peroxisome proliferator-activated receptor $\gamma$ C161T polymorphism on lipid profile in Brazilian patients with type 2 diabetes mellitus. J Endocrinol Invest 2005;28(2):129-36.

48. Kersten S, Desvergne B, Wahli W. Roles of PPARs in health and disease. Nature 2000;405:421-4.

49. Tavares V, Hirata RDC, Hirata MH. Ação dos PPARs no metabolismo de lipídeos, homeostase da glicose e inflamação. Rev Newslab 2003;57:128-44.

50. Jiang C, Ting AT, Seed B. PPAR $\gamma$ agonists inhibit production of monocyte inflammatory cytokines. Nature 1998;391:82-6.

51. Ricote M, Huang JT, Welch JS, Glass CK. The peroxisome proliferators-activated receptor (PPAR $\gamma$ ) as a regulator of monocyte/macrophage function. J Leukoc Biol 1999;66:733-9.

52. Tontonoz P, Nagy L, Alvarez JG, Thomazy VA, Evans RM. PPAR promotes monocyte/macrophage differentiation and uptake of oxidized LDL. Cell 1998;93:241-52.

53. Hu E, Kim JB, Sarraf $P$, Spiegelman BM. Inhibition of adipogenesis through MAP kinase-mediated phosphorylation of PPAR $\gamma$. Science 1996;274:2100-3.

54. Moore KJ, Rosen ED, Fitzgerald ML, Randow F, Andersson $L P$, Altshuler D, et al. The role of PPAR $\gamma$ in macrophage differentiation and cholesterol uptake. Nat Med 2001;7:41-7.

55. Lehmann JM. An antidiabetic thiazolidinedione is a high affinity ligand for peroxisome proliferators-activated receptor gamma (PPAR $\gamma$ ). J Biol Chem 1995;270:12953-6.

56. DREAM (Diabetes Reduction Assessment with ramipril and rosiglitazone Medication) Trial Investigators. Effect of rosiglitazone on the frequency of diabetes in patients with impaired glucose tolerance or impaired fasting glucose: a randomized controlled trial. Lancet 2006;368:1096-105.

57. Frias JP, Yu JG, Kruszynska YT, Olefsky JM. Metabolic effects of troglitazone therapy in type 2 diabetic, obese, and lean normal subjects. Diabetes Care 2000;23:64-9.

58. Miyazaki Y. Improved glycemic control and enhanced insulin sensitivity in type 2 diabetic subjects treated with pioglitazone. Diabetes Care 2001;24:710-9.

59. Sironi AM. Effects of troglitazone on insulin action and cardiovascular risk factors in patients with non-insulin-dependent diabetes. Clin Pharmacol Ther 1997;62:194-202.

60. Mudaliar S, Chang AR, Henry RR. Thiazolidinediones, peripheral edema, and type 2 diabetes: incidence, pathophysiology, and clinical implications. Endocr Pract 2003;9:406-16.

61. Larsen TM, Toubro S, Astrup A. PPAR y agonists in the treatment of type II diabetes: is increased fatness commensurate with long-term efficacy? Int J Obes Relat Metab Disord 2003;27:147-61.

62. Sewter CP, Blows F, Vidal-Puig A, O'Rahilly S. Regional differences in the response of human pre-adipocytes to PPAR $\gamma$ and $R X R \alpha$ agonists. Diabetes 2002;51:718-23.

63. Garg A. Regional adiposity and insulin resistance. J Clin Endocrinol Metab 2004;89:4206-10.

64. Trujillo ME, Scherer PE. Adiponectin: journey from an adipocyte secretory protein to biomarker of the metabolic syndrome. J Intern Med 2005;257:167-75. 
65. Yu JG. The effect of thiazolidinediones on plasma adiponectin levels in normal, obese and type 2 diabetec subjects. Diabetes 2002;51:2968-74.

66. Li W, Tonelli J, Kishore P, Owen R, Goodman E, Scherer PE, et al. Insulin-sensitizing effects of thiazolidinediones are not linked to adiponectin receptor expression in human fat or muscle. Am J Physiol Endocrinol Metab 2007; [Epub ahead of print].

67. Kern PA, Di Gregorio GB, Lu T, Rassouli N, Ranganathan G. Adiponectin expression from human adipose tissue: relation to obesity, insulin resistance, and tumor necrosis factor alpha expression. Diabetes 2003;52:1779-85.

68. Yang WS. Synthetic peroxisome proliferators-activated receptor- $\gamma$ agonist, rosiglitazone, increases plasma levels of adiponectin in type 2 diabetic patients. Diabetes Care 2002;25:376-80.
69. Loviscach M. Distribution of peroxisome proliferators-activated receptors (PPARs) in human skeletal muscle and adipose tissue: relation to insulin action. Diabetologia 2000;43:30411.

70. Yonemitsu S. Troglitazone induces GLUT4 translocation in L6 myotubes. Diabetes 2001;50:1093-101.

Endereço para correspondência:

Vladimir Tavares

Av. Prof. Lineu Prestes 580, bloco 17

05508-900 São Paulo, SP

Fax: (11) 3813-2197

E-mail: vladitav@usp.br 